doi:10.12662/2359-618xregea.v8i1.p150-163.2019

ARTIGOS

\title{
CARACTERÍSTICAS EMPREENDEDORAS DO DISCENTE DO CURSO DE ENGENHARIA DE PRODUÇÃO NA INDÚSTRIA 4.0
}

\author{
ENTREPRENEURSHIP CHARACTERISTICS OF THE \\ COURSE OF PRODUCTION ENGINEERING COURSE IN \\ THE INDUSTRY 4.0
}

\author{
CARACTERÍSTICAS EMPRENDEDORAS DE LOS \\ DISCENTES DEL CURSO DE INGENIERÍA DE \\ PRODUCCIÓN EN LA INDUSTRIA 4.0
}

\section{RESUMO}

A Quarta Revolução Industrial traz consigo as potencialidades da evolução da tecnologia da informação e do conhecimento. Esse novo cenário impacta na produção, consumo, organização da sociedade e das relações de trabalho. Este artigo tem por objetivo geral identificar, por meio da percepção docente, as características empreendedoras consideradas como mais importantes para a formação do engenheiro de produção que

Mariana Augusta de Araújo Silva

Mestrado em Engenharia de Produção (UFRN). Especialização em Marketing (UnP). Graduação em Administração (UnP). Professora do Centro Universitário Christus. Fortaleza - CE - BR. E-mail: $<$ marianaangusta@live.com>.

Bryan Abreu Reategui Graduando em Engenharia de Produção pelo Centro Universitário Christus. Fortaleza - CE - BR. E-mail: $<$ b_reategui@yahho.com.br $>$.

Cesar Bündchen Záccaro de Oliveira

Doutor em Engenharia de Processos (UNIT). Professor do Centro Universitário Christus. Fortaleza - CE - BR. E-mail: $<$ cesarbundchen@hotmail. com>. pretende atuar na indústria 4.0. A abordagem da pesquisa é quantitativa. Quanto aos objetivos, é exploratória descritiva, com levantamento de dados por meio do Survey. O objeto de investigação são todos os professores do Curso de Engenharia de Produção de uma IES no estado do Ceará. Conclui-se que as informações e os conhecimentos coletados contribuem para que as IES e os professores superem desafios na promoção da inclusão da temática da Indústria 4.0 dentro da academia e dos conceitos do empreendedor para a formação integral do discente focado na atuação diferenciada no mercado de trabalho.

Palavras-chave: Engenharia de Produção. Práticas pedagógicas. Formação complementar. Empreendedor. Indústria 4.0.

\begin{abstract}
The Fourth Industrial Revolution brings with it the potential of the evolution of information and knowledge technology. This new scenario impacts on production, consumption, organization of society and labor relations. This article aims to identify, through the teacher's perception, the entrepreneurial characteristics considered as most important for the formation of the Production Engineer that intends to work in the industry 4.0. The research approach is quantitative. The objectives are descriptive
\end{abstract}


exploratory, with data collection through the Survey. The research object is all teachers of the Production Engineering Course of an IES in the state of Ceará, Brazil. It is concluded that the information and knowledge collected contribute to the IES by enabling the teachers to overcome challenges in promoting the inclusion of the theme of Industry 4.0 within the academy and the concepts of the entrepreneur for the integral formation of the student focused on the differentiated performance in the labor market.

Keywords: Production Engineering. Pedagogical practices. Complementary training. Entrepreneur. Industry 4.0.

\section{RESUMEN}

La Cuarta Revolución Industrial trae consigo las potencialidades de la revolución de la tecnología de la información y del conocimiento. Ese nuevo panorama impacta en la producción, consumo, organización de la sociedad y de las relaciones de trabajo. Este artículo tiene por objetivo general identificar, a través de la percepción docente, las características emprendedoras consideradas como más importantes para la formación del Ingeniero de Producción que pretende actuar en la industria 4.0. El abordaje de la pesquisa es cuantitativo. Cuanto a los objetivos es exploratorio descriptivo, con levantamientos de datos a través del Survey. El objetivo de investigación son todos los profesores del Curso de Ingeniería de Producción de una IES en el estado de Ceará. Se puede concluir que las informaciones y conocimientos recolectados contribuyen para que las IES y los profesores superen desafíos en la promoción de la inclusión de la temática de la Industria 4.0 dentro de la academia y de los conceptos del emprendedor para la formación integral del discente concentrado en la actuación diferenciada en el mercado de trabajo.

Palabras-clave: Ingeniería de Producción. Prácticas pedagógicas. Formación complementar. Emprender. Industria. 4.0.

\section{INTRODUÇÃO}

O Mercado de trabalho sofre influências diretas das mudanças sociais, políticas, econômicas e mercadológicas (PAZ; MACHADO, 2016). Nesse sentido, a transformação que está acontecendo nas relações de consumo e na inserção da tecnologia provoca uma reflexão sobre a posição dos engenheiros de produção no contexto advindo pela Indústria 4.0.

Em virtude dessa reflexão, busca-se aprofundar o pensamento na forma de como capacitar os discentes do curso de Engenharia de Produção para que eles absorvam as melhores oportunidades de trabalho, ao acrescentar em sua formação profissional conhecimentos acerca das questões relacionadas às habilidades empreendedoras.

A indústria 4.0 é um ramo ascendente, o termo é resultado de diversos estágios históricos de revoluções industriais (BALASINGHAM, 2016). Deve-se considerar, portanto, que as mudanças advindas desde a primeira revolução industrial, exigiram que os profissionais desenvolvessem características específicas para acompanhar a evolução de cada tempo no desempenho de suas atividades laborais.

No que tange à Quarta Revolução Industrial, as múltiplas habilidades tratadas no referencial teórico como a capacidade de criar em contextos adversos, são possíveis de serem desenvolvidas junto ao discente, ainda durante o ensino superior, no curso da graduação.

Conforme Bernardi (2016, p. 40), "os currículos foram desenvolvidos a partir dos principais objetivos de aprendizagem que definem o perfil do Engenheiro 4.0." Ainda cita que, entre eles desenvolve conhecimento técnico, habilidades de Design, habilidades empreendedoras, consciência do contexto, habilidades de relacionamento interpessoal, e habilidade de "aprender a aprender", ou seja, de como fazer para aprender o que não se sabe.

O Curso de Engenharia de Produção é bastante influenciado pela indústria. Piratelli (2005) ressalta que a Engenharia de Produção foi criada visando à racionalidade econômica aplicada aos sistemas de produção, ao estudo de arranjos físicos em indústrias, à programação da produção. Em 
sua forma mais ampla e genérica, resolver os problemas das fábricas, hoje chamadas de "indústria".

Dessa forma, este artigo tem por objetivo geral identificar, por meio da percepção docente, as características empreendedoras consideradas como mais importantes para a formação do Engenheiro de Produção que pretende atuar na indústria 4.0. Quanto aos objetivos específicos procurou-se verificar se o docente considera que o conceito da Indústria 4.0 é relevante para a formação do aluno de Engenharia de Produção, bem como se é importante a formação empreendedora dentro do Curso de Engenharia de Produção, identificar as atividade(s) complementar(es) que ele considera como mais importante(s) para a formação empreendedora dos discentes e quais as habilidades empreendedoras que ele considera mais ausentes nos discentes.

Para apresentar os fundamentos sobre os quais a pesquisa se apoiou e as bases teóricas utilizadas para dar suporte às análises dos dados, foi realizada uma pesquisa bibliográfica sobre o ensino de engenharia no Brasil, sobre as características do empreendedor, sobre a indústria 4.0 e as características que ela demanda de um profissional para atuar com eficácia no contexto da indústria 4.0.

Para o estudo de caso, a metodologia abordada foi uma survey que, direcionada para os docentes, proporcionou coletar informações acerca dos objetivos traçados no desenvolvimento do trabalho. Este artigo teve a pretensão de contribuir para que a temática fosse discutida no âmbito acadêmico. A relevância do estudo se dá por meio da busca de elementos importantes que favoreçam o desenvolvimento de ações que complementam o ensino com foco na promoção das habilidades empreendedoras no contexto do mercado de trabalho no âmbito da indústria 4.0.

$\mathrm{O}$ artigo foi estruturado em cinco seções. A primeira seção é constituída pela introdução. $\mathrm{Na}$ segunda seção, discute-se a revisão da literatura com os tópicos práticas pedagógicas, formação complementar, empreendedor e Indústria 4.0. A terceira seção descreve o percurso metodológico da pesquisa. Na quarta seção, são realizadas a apresentação e a análise das informações; a quinta seção expõe a conclusão do estudo.

\section{REVISÃO DE LITERATURA}

A Resolução CNE/CES n ${ }^{\circ}$ 11/2002 apresenta que o ensino de Engenharia deve estar de acordo com as exigências impostas pela globalização. "Art. $3^{\circ}$ - A formação do engenheiro deve ser generalista, humanista, crítica e reflexiva, que o capacite a absorver novas informações e atuar sobre elas, estimulando sua criatividade na identificação e resolução de problemas." (CONSELHO NACIONAL DE EDUCAÇÃO, 2002, p. 1).

Segundo Khan (2013) o modelo de ensino que hoje é aplicado nas escolas e instituições de ensino superior foi fundamentado na Prússia no século XVIII, antes mesmo da Revolução Industrial. Para Silva e Mascarenhas (2016), essa forma de ensinar se assemelha a uma produção padronizada de profissionais, de forma semelhante a uma linha de produção, como se fosse uma fábrica.

Para Burke (2003), as escolas estão condicionando os alunos com conhecimento que eles precisariam ter no passado, sendo que os alunos precisam sair da escola para viver não no passado ou no presente, mas sim, no futuro, com sua imprevisibilidade.

Em paralelo às possibilidades de ensino, com o intuito de diminuir custos, cada vez mais ocorrem movimentos de reengenharia e enxugamento de estruturas de grandes corporações. O downsizing, que em português significa "achatamento" se caracteriza por ser "uma da técnica empregada para tornar a empresa ágil e competitiva, e normalmente é a primeira ferramenta utilizada para iniciar processos de horizontalização nas empresas e reestruturação dos recursos humanos." (FERREIRA, 2004, p. 2). Esse movimento estimula a migração de muitos profissionais que atuavam em postos executivos a irem para o magistério, o que para as instituições de ensino se torna algo "positivo", pois é absorvida uma parcela de profissionais com experiências mercadológicas que podem contribuir para a formação complementar dos discentes quanto aos aspectos de exigência do mercado de trabalho. Isso provoca no discente a oportunidade de entender o contexto profissional no qual estará inserido após a sua graduação. 
As disciplinas da estrutura curricular dos cursos de Engenharia se caracterizam como sendo uma maneira de delimitar o conteúdo abordado a fim de estudar dentro de um determinado ângulo de visão. Porém, esse ângulo muitas vezes pode ser limitado e fragmentado se comparado com a diversidade de informações necessárias a serem processadas no dia a dia.

Segundo Amboni et al. (2012, p. 302) "a visão fragmentada do saber começa a ser questionada, por ser insuficiente frente às situações de instabilidade, imprevisibilidade, incerteza, contradições, paradoxos, conflitos e desafios." Esse olhar fragmentado, passa a fazer parte do perfil profissional do futuro egresso, que, pela complexidade nas relações de trabalho, não gera resultados em um contexto de rede dinâmica e aberta, como será exposto no tópico referente à Indústria 4.0.

\subsection{PRÁTICAS PEDAGÓGICAS}

O construtivismo diz que o conhecimento é adquirido pela interação do indivíduo com seu meio externo, e ocorre de forma diferente e única. Assim, por meio de diversas atividades, um está continuamente aprendendo algo novo baseado em seu conhecimento atual (MARKHAM; LARMER; RAVITZ, 2008). Explica que os indivíduos constroem o conhecimento por intermédio das interações com seu ambiente, e a construção do conhecimento de cada indivíduo é diferente. Assim, por meio da condução das investigações, conversações ou atividades, um indivíduo está aprendendo a construir um conhecimento novo tendo como base seu conhecimento atual (MARKHAM; LARMER; RAVITZ, 2008).

A educação baseia-se em quatro pilares: aprender a conhecer, aprender a fazer, aprender a conviver e aprender a ser (DELORS, 1998).

A teoria da aprendizagem diz que conhecimento, pensamento, ação e contexto de aprendizagem estão sempre relacionados. Assim, a aprendizagem é, em parte, uma atividade social que ocorre dentro de um contexto cultural, comunitário e relacionada com as experiências anteriores (MARKHAM; LARMER; RAVITZ, 2008).
A preparação dos professores constitui a questão primordial de todas as reformas pedagógicas. Conforme Maslow (1975), os docentes podem ser agrupados em dois grupos: os objetivistas (que se orientam pelas necessidades exteriores do educando) e os subjetivistas (que consideram o educando possuidor de personalidade própria, consciência e criatividade em busca de conhecimento autorrealizador).

O professor não deve mostrar e sim ajudar o aluno a enxergar e a descobrir com ele, além de incentivar e apostar no potencial do aluno, deve escutar com atenção, sem jamais permitir chantagens emocionais. Educar é exigir e não fazer o que o aluno quer. Guimarães (2003) enfatiza que quando ambos, hábitos e conhecimentos, combinados com a motivação, são satisfatórios, o sujeito percebe que foi ele quem causou a mudança desejada.

Para Berbel (2011) as metodologias ativas baseiam-se em formas de desenvolver os processos de aprender, utilizando experiências reais ou simuladas, visando às condições de solucionar, com sucesso, desafios advindos das atividades essenciais da prática social em diferentes contextos. Elas têm o potencial de despertar a curiosidade, à medida que os alunos se inserem na teorização e trazem elementos novos, ainda não considerados nas aulas ou na própria perspectiva do professor.

O estudo de caso é uma delas. O aluno é levado à análise de problemas e à tomada de decisões. É um método caracterizado pelo uso de problemas do mundo real para encorajar os alunos a desenvolver pensamento crítico e habilidades de solução de problemas e a adquirir conhecimento sobre os conceitos essenciais da área em questão (RIBEIRO et al., 2003). "O caso pode ser real, fictício ou adaptado da realidade", enfatizam Abreu e Masetto (1985, p. 69). Pode ser utilizado antes de um estudo teórico de um tema com a finalidade de estimular os alunos ao estudo.

O método de projetos, segundo Bordenave e Pereira (1982), é uma modalidade que pode associar atividades de ensino, pesquisa e extensão; tem como principal objetivo lutar contra a artificialidade da escola e aproximá-la o mais possível da realidade da vida por meio de 4 fases: 1 intenção - curiosidade e desejo de resolver uma 
situação concreta; 2 preparação - estudo e busca dos meios necessários para a solução; 3 execução - aplicação dos meios de trabalho escolhidos e 4 apreciação - avaliação do trabalho realizado. A pesquisa científica também é uma modalidade de atividade bastante estimulada junto aos alunos do ensino superior, que a podem desenvolver como uma iniciação científica, inserindo-se como colaboradores em projetos de professores, entre outras possibilidades, conceitua Berbel (2011).

Em atividades como a visita técnica é preciso fazer as observações previstas e registrar os dados, as informações e as observações, relatam Abreu e Masetto (1985), sempre promovendo o encontro entre o que está sendo estudado e a realidade visitada. Os estágios precisam ter o envolvimento de todas as partes, tanto do aluno quanto da faculdade e da empresa. Todos os envolvidos precisam saber sobre o planejado para explicitar os objetivos da aprendizagem naquele estágio.

A interdisciplinaridade surge, assim, da ideia de que para compreender a complexa realidade, é necessário relacionar os diferentes conteúdos das disciplinas, ou seja, interagir em diferentes áreas do conhecimento à procura de um entendimento mais global e não fragmentado (JAPIASSU, 1976). A interdisciplinaridade envolve a integração e o engajamento de educadores, em um trabalho conjunto de interação de disciplinas do currículo escolar. Japiassu (1976, p. 52) afirma que "trata -se de um gigantesco mas indispensável esforço que muitos pesquisadores realizam para superar o estatuto de fixidez das disciplinas e para fazê-las convergir pelo estabelecimento de elos e de pontes entre os problemas que elas colocam."

\subsection{FORMAÇÃO COMPLEMENTAR}

Atualmente, o termo "formação complementar" muitas vezes é compreendido pelas IES como parte integrante da matriz curricular no que tange a atividades como: projetos de pesquisa, projetos de extensão, monitorias, participação em congressos, publicações, apresentação de trabalhos em congressos e outros (MASETTO, 2001). Sendo elas, em sua maioria, buscadas pelo discente como forma de completar as horas previstas na matriz curricular.
Em muitos casos, também, não sendo aproveitadas pelo curso superior por não "compreenderem" as áreas delimitadas pelas instituições e suas coordenações de curso, como sendo compatíveis com a área de formação do graduando.

No entanto, os estudantes necessitam da aquisição, tanto de conhecimentos como de habilidades para se inserirem no contexto social. Entende-se competência como a habilidade adquirida com o estudo de determinado assunto, conforme afirma Chiavenato (2003).

Em paralelo, as organizações deste século buscam a competitividade em seu meio de negócio. Neste ambiente, "os fatores de competências de seus profissionais são considerados e valorizados como uma mola propulsora da gestão do empreendimento." (GUIMARÃES; GOULART, 2011, p. 1). Em consequência disso, é exigida alta capacidade de adaptação e desenvolvimento constantes de novos parâmetros de qualidade, novas exigências e novas competências organizacionais.

As competências gerenciais "são geralmente concebidas como resultado de um conjunto de conhecimentos, habilidades e atributos que o gerente emprega em determinada situação para agregar valor à organização e aos indivíduos." (ODERICH, 2005, p. 90).

A sobrevivência tanto profissional quanto organizacional depende cada vez mais da capacidade de absorver o novo e elaborar respostas adaptativas às mudanças. Conforme a ABEPRO (1998), o cenário mundial de atuação das empresas está vinculado hoje ao processo de internacionalização e globalização da economia. $\mathrm{O}$ binômio produtividade/qualidade tornou-se uma necessidade competitiva de interesse global não apenas de empresas de bens e serviços, mas também de inúmeras nações.

Conforme Masetto (2001, p. 22):

Dessa forma o Ensino Superior é desafiador, pois precisa ser inventado ou reinventado diariamente. E educação é considerar que o mundo social faz parte do cotidiano e, portanto, está presente na vida do acadêmico. Nenhum conteúdo é tão completo a ponto de ignorar as transformações que ocorrem diariamente na sociedade. 
Para Berbel (2011, p. 25) "A complexidade crescente dos diversos setores no âmbito mundial, nacional e local tem demandado o desenvolvimento de capacidades humanas de pensar, sentir e agir de modo cada vez mais amplo e profundo, comprometido com as questões do entorno em que se vive."

Assim, consideramos o perfil a seguir, conhecido como empreendedor, que se destaca com suas características diferenciadas, conforme será explanado na próxima sessão.

\subsection{O EMPREENDEDOR}

Para a Endeavor Brasil (2018), organização líder no apoio a empreendedores de alto impacto ao redor do mundo, o empreendedorismo é a disposição para identificar problemas e oportunidades e investir recursos e competências na criação de um negócio, projeto ou movimento que seja capaz de alavancar mudanças e gerar um impacto positivo. Sua prática é tema que se desenvolve em forma crescente de estudos nas diversas áreas, principalmente por destacar o perfil do profissional empreendedor como diferenciador.

Por trás dessas invenções, existem pessoas ou equipes de pessoas com características especiais que são visionárias, questionam, arriscam, querem algo diferente, fazem acontecer e empreendem. Os empreendedores são pessoas diferenciadas, que possuem motivação singular; apaixonadas pelo que fazem, não se contentam em ser mais um na multidão e querem ser reconhecidas e admiradas, referenciadas e imitadas, querem deixar um legado. Uma vez que os empreendedores estão revolucionando o mundo, seu comportamento e o próprio processo empreendedor devem ser estudados e entendidos (DORNELAS, 2012, p. 7).

No mundo dos negócios, em que os cenários mudam rapidamente, o perfil empreendedor ganha destaque por desenvolver, entre habilidades essenciais às organizações inovadoras, a capacidade de se adaptar velozmente às mudanças, por meio de atitudes proativas que dão sustentabilidade de previsão de cenários futuros. Continuando a citar referências sobre as características desse profissional, Filion (1999), acrescenta a criatividade, marcada pela capacidade de estabelecer e atingir objetivos e que mantém um alto nível de consciência do ambiente em que vive, usando-a para detectar oportunidades de negócios.

Um empreendedor que continua a aprender a respeito de possíveis oportunidades de negócios e a tomar decisões moderadamente, destaca-se pela incessante busca do conhecimento, pois acredita que seja esse o combustível para sempre inventar.

\begin{abstract}
Nos últimos anos em diversos países surgiram modelos e experiências que relatam a aplicação de programas promotores do empreendedorismo. Partindo-se do pressuposto de que o empreendedorismo e as competências a ele inerentes não são algo exclusivamente intrínseco ao ser humano, mas que podem ser aprendidas e influenciadas pelo ambiente e estímulos externos, que vão desde os círculos mais restritos da família e amigos até às instituições em que os indivíduos se inserem, e mesmo ao contexto nacional e regional do campo de atuação de cada um (COSTA; CARVALHO, 2011, p. 108).
\end{abstract}

As habilidades do empreendedor, conforme Dornelas (2012) compreendem três aspectos, nas áreas: técnicas, em que se identificam os quesitos como saber escrever, saber ouvir, captar informações, ser organizado, trabalhar em equipe, know-how técnico em sua área; pessoais, compreendidas como capacidade de assumir riscos, ser disciplinado, inovador, líder visionário, persistente, ser voltado para mudanças. Por fim, as gerenciais, que incluem as áreas envolvidas na criação, desenvolvimento e gerenciamento de uma nova empresa: marketing, administração, finanças, operacional, produção, tomada de decisão, visão sistêmica e ser um bom negociador.

Corroborando, Oliveira (2010) acrescenta habilidades de:

Forças que podem impulsionar as empresas, a citar criatividade e inovação, vantagem tecnológica, os processos 
bem sintonizados e a geração otimizada de valor, a obsessão com a qualidade, principalmente dos processos, das informações e das decisões, a cultura organizacional baseada em melhoria contínua e aprendizado, bem como trabalho em equipes multidisciplinares (OLIVEIRA, 2010, p. 117).

Para a obtenção de uma visão globalizada, internacionalizada desse perfil, Peiris Akoorie e Sinha (2012) elaboraram, por meio de um estudo das principais publicações norte-americanas relacionadas ao tema, resumidas na Tabela 1 , as fundamentais competências empreendedoras.

Tabela 1 - Competências empreendedoras

\begin{tabular}{c|c}
\hline $\begin{array}{c}\text { COMPETÊNCIAS } \\
\text { EMPREENDEDORAS }\end{array}$ & FREQUÊNCIA \% \\
\hline Foco/Visão/Intenção global & 22 \\
\hline $\begin{array}{c}\text { Capacidade de rede/ } \\
\text { Conhecimento }\end{array}$ & 20 \\
\hline Conhecimento Técnico & 13 \\
\hline Compromisso & 13 \\
\hline Criatividade e Inovação & 13 \\
\hline Tomada de risco & 12 \\
\hline Atitude & 10 \\
\hline Aprendizagem experiencial & 10 \\
\hline Pró-atividade & 10 \\
\hline Conhecimento Prático & 8 \\
\hline Educação & 7 \\
\hline Capacidade de identificar & 7 \\
\hline oportunidades & 5 \\
\hline Autoconfiança e autoeficácia & 4 \\
\hline Persistência e perseverança & \\
\hline
\end{tabular}

Fonte: (PEIRIS; AKOORIE; SINHA, 2012, p. 294, tradução nossa).

Sendo listados, em ordem decrescente: foco, visão, intenção global, capacidade de rede, conhecimento, conhecimento técnico, compromisso, habilidades, competências, criatividade e inovação, Tomada de risco, Atitude, aprendizagem experiencial, pró-atividade, Conhecimento experiencial, educação. Essas competências caracterizam profissionais diferenciados, pois, em uma visão macro, permeiam os estímulos para constantes adaptações ao longo da profissão. Dornelas (2012) considera que o momento atual, nada mais é do que a representação da era do empreendedorismo, pois são os empreendedores e/ou empreendedores corporativos, que estão eliminando barreiras comerciais e culturais, encurtando distâncias, globalizando e renovando os conceitos econômicos, criando novas relações de trabalho e novos empregos, quebrando paradigmas e gerando riqueza para a sociedade.

Os empreendedores corporativos ou intraempreendedores enxergam nos problemas do dia a dia, oportunidades de crescimento para a empresa, sendo capazes de inovar sistêmica e constantemente, dentro da organização em que trabalha (ENDEAVOR BRASIL, 2018).

Para Penã (2012) a inovação é uma força que vem do empreendedorismo e de sua aplicação. Entender as habilidades, citadas anteriormente, favorece o embasamento da subseção a seguir, em que se identifica o contexto para o qual o desenvolvimento profissional impactará positivamente no que tange às habilidades empreendedoras no exercício da profissão ou na criação de negócios.

\subsection{INDÚSTRIA 4.0}

Atualmente estamos na Quarta Revolução Industrial. Segundo Almeida (2005), o que mais impulsionará essa revolução é, entre outros fatores, um conjunto multidisciplinar de ciências exatas e cognitivas.

A Primeira Revolução Industrial teve como característica a invenção e a utilização das máquinas a vapor na indústria. A Segunda Revolução Industrial teve como principal característica o advento da energia elétrica como facilitadora de processos ou do processo produtivo. A Terceira Revolução Industrial tem como principal característica os avanços da eletrônica digital e da automação de processos produtivos. A Quarta Revolução Industrial possui como característica 4 revoluções em diferentes ramos ao mesmo tempo: biotecnologia, nanotecnologia e inteligência artificial (DELOITTE, 2014; MCKINSEY, 2016; SCHWAB, 2016).

Para Morais e Monteiro (2016), a Indústria 4.0 consiste na produção inteligente dos mais di- 
versos recursos. Para isso, geralmente se utiliza o conceito de "Smart Factory" ou fábrica inteligente. "Smart factory" é uma fábrica que faz produtos inteligentes, em equipamentos inteligentes, em cadeias de abastecimento inteligentes (COELHO, 2016, p. 15). Consiste em um conjunto de facilitadores digitais de sensores que interagem entre si.

A internet das coisas, conforme Magrani (2018, p. 20),

De maneira geral, pode ser entendido como um ambiente de objetos físicos interconectados com a internet por meio de sensores pequenos e embutidos, criando um ecossistema de computação onipresente (ubíqua), voltado para a facilitação do cotidiano das pessoas, introduzindo soluções funcionais nos processos do dia a dia.

Com o grande avanço na inteligência artificial, as próprias máquinas coletam seus dados, transformam em informações, fazem a tomada de decisão mais apropriada e controlam o resultado. Profissionais que possuem empregos padronizados ou repetitivos têm muita chance de serem substituídos por uma máquina no decorrer dos anos.

Segundo Aires, Moreira e Freire (2017), duas das características mais buscadas na Quarta Revolução Industrial compreendem a criatividade e a boa comunicação. Isso se dá, pois a máquina, em sua maioria, não possui uma capacidade de inovar, ou seja, fazer algo para qual não foi programada. Ainda segundo Morais e Monteiro (2016), a fusão das áreas de conhecimento é um aspecto importante a ser tratado quando se fala em Indústria 4.0.

Para Coelho (2016), a indústria terá as seguintes alterações: clientes mais exigentes, produtos inteligentes, novas formas de colaboração, transformação do operacional em digital. Para Coelho (2016), o cliente está cada vez mais interessado nas experiências envolvidas na compra e não somente no produto. Todo o processo de compra, da embalagem até o serviço pós-venda, é um fator qualificador para a efetivação da venda. Essa mudança de paradigma obriga as empresas a contratarem profissionais que se adaptem a mudanças de mercado com maior facilidade.

\section{PROCEDIMENTOS METODOLÓGICOS}

A estratégia utilizada neste trabalho foi o estudo de caso. Segundo Yin (2015), o estudo de caso é ideal para seu foco está em estudar um comportamento contemporâneo. Ainda segundo Yin (2015), fazer um estudo de caso de forma apropriada significa ter em vista cinco preocupações tradicionais sobre estudos de caso - conduzir a pesquisa de forma rigorosa, evitar confusões com casos de ensino, saber como chegar a conclusões generalizadas quando desejado, gerir cuidadosamente o nível de esforço e compreender a vantagem comparativa da pesquisa de estudo de caso.

O método de coleta escolhido foi o Survey, por meio do instrumento de pesquisa, um questionário semiestruturado com sete questões, abertas e fechadas, seguindo a composição das perguntas baseando-se no autor Oliveira (2010).

O universo compreende 130 professores (ativos e inativos) do Curso de Engenharia de Produção de uma Instituição Estadual de Ensino Superior localizada em Fortaleza/CE, constituindo assim, uma pesquisa censitária. Com relação ao retorno dos questionários, enviados por e-mail, aos docentes, obteve-se um retorno de 107 questionários respondidos. Dessa forma, a amostra deste estudo é representativa no nível de $95 \%$ de confiança. Para ser válida, tal pesquisa deveria abranger, pelo menos, 98 docentes (erro amostral de 5\%), de acordo com a fórmula do cálculo amostral extraída de Medina (2013).

A pesquisa teve sua aplicação durante os meses de agosto e setembro de 2017.

A análise e a compilação dos dados ocorreram por meio do uso do Microsoft Excel, em que os dados foram transformados em informação por meio da aplicação de gráficos.

\section{RESULTADOS}

No Gráfico 1, quando perguntados sobre a relevância do conceito da indústria 4.0 na formação do Engenheiro de Produção, a maioria representada por $95 \%$ dos entrevistados, responderam que consideram o conceito como relevante para a formação do Engenheiro de Produção. 
Gráfico 1 - Você considera que o conceito da Indústria 4.0 é relevante para a formação do aluno de Engenharia de Produção?

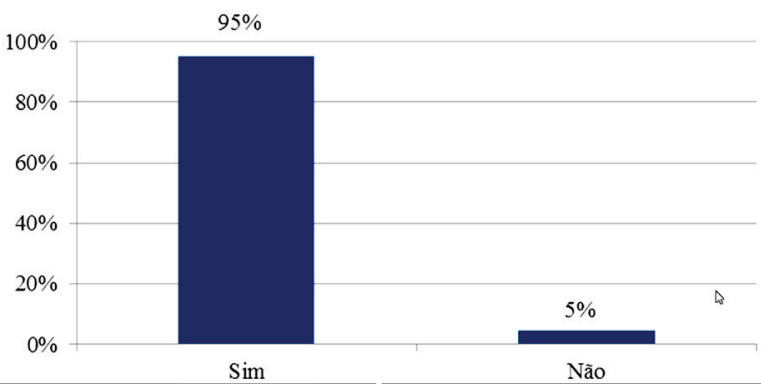

Fonte: dados da pesquisa (2017).

Entre as justificativas, coletadas por meio das perguntas abertas, os docentes afirmaram que havia grande preocupação de preparar o aluno para o futuro; porém, considerando os conceitos atuais, postos no currículo do curso, como referência. Entre as respostas negativas, a justificativa foi que o aluno é quem deve buscar informações sobre a indústria 4.0.

Gráfico 2 - Você considera importante a formação empreendedora dentro do Curso de Engenharia de Produção?

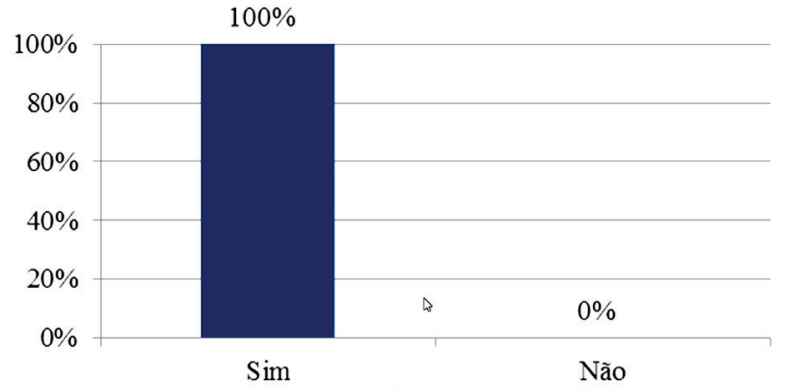

Fonte: dados da pesquisa (2017).

Em relação à formação empreendedora no Curso de Engenharia de Produção (Gráfico 2), $100 \%$ do público pesquisado respondeu "sim", concordando que é importante esse tipo de formação. Os poucos pesquisados que justificaram a resposta, afirmaram que é importante, pois o "empreendedorismo é a disciplina chave do curso". Alguns afirmaram que diversos alunos apenas fazem o Curso de Engenharia de Produção para ter uma formação empreendedora.
Gráfico 3 - Você fala ou já falou sobre "o empreendedorismo" para seus alunos?

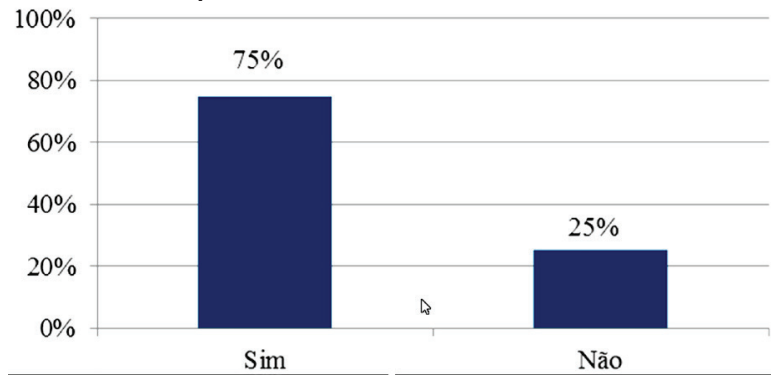

Fonte: dados da pesquisa (2017).

Conforme o Gráfico 3, foi perguntado se o professor fala, ou não, sobre o empreendedorismo para os alunos. $75 \%$ dos professores disseram que sim. A justificativa era que, nas disciplinas que ministram, alguns alunos perguntavam se "a disciplina poderia gerar lucro". Para melhor responder, o professor tinha que elaborar casos em que a disciplina gerasse lucro, explorando uma necessidade do mercado. Os professores que responderam negativo, poucos justificaram, mas quem justificou afirmou que, por não ministrar a disciplina de empreendedorismo, não considerava importante fazer o respectivo link com a disciplina, pois consideram que os alunos ainda irão conhecer com outro professor.

Gráfico 4 - Com base nas características empreendedoras, marque as que você considera como mais importantes para a formação do Engenheiro de Produção, que pretende ingressar na indústria 4.0

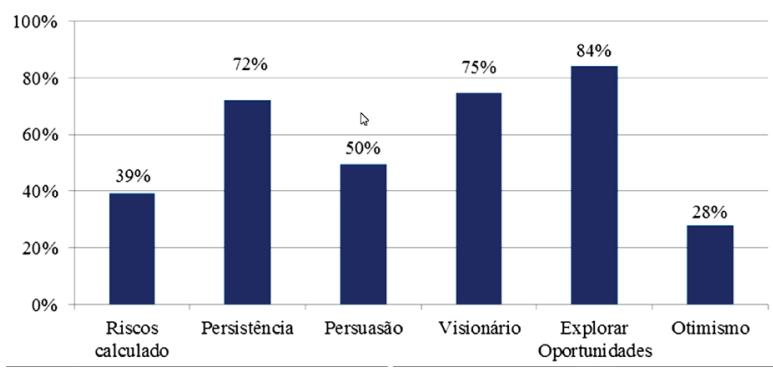

Fonte: dados da pesquisa (2017).

Quando perguntado sobre as características empreendedoras (Gráfico 4), citadas no referencial por Peiris, Akoorie e Sinha (2012) cada professor poderia marcar quantas caracte- 
rísticas desejasse. A maioria com $84 \%$ escolheu Explorar Oportunidades, seguido com Visionário com $75 \%$ e Persistência com $72 \%$, como características principais. Poucos entrevistados quiseram propor outra característica, embora 4 professores propusessem como "Sorte" sendo uma característica.

Gráfico 5 - Marque a(s) atividade(s) complemen$\operatorname{tar}(\mathrm{es})$ que você considera mais importante para a formação empreendedora do aluno que pretende ingressar na indústria 4.0 ?

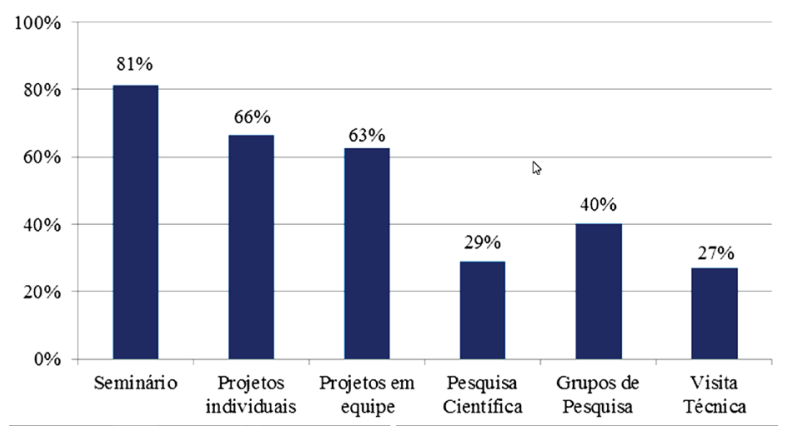

Fonte: dados da pesquisa (2017).

Sobre as atividades que auxiliam na formação empreendedora (Gráfico 5), o Seminário recebeu uma vantagem significativa com $81 \% \mathrm{em}$ relação às demais. A justificativa que mais se repetiu foi citada na questão aberta como: "alguém que apresenta um bom seminário e sabe falar bem em público, consegue expor suas ideias da melhor forma", e isso ajudaria no entendimento acerca da indústria 4.0. Segundo Aires, Moreira e Freire (2017), duas das características mais buscadas na Quarta Revolução Industrial compreendem a criatividade e a boa comunicação.

Projetos individuais com $66 \%$ de citações e projetos em equipe com $63 \%$ ficaram emparelhados com o número de votos. As justificativas que mais se repetiram, foram que, muitas vezes, ou o "engenheiro irá trabalhar sozinho fazendo tudo" ou "irá trabalhar com um conjunto de pessoas interdisciplinares e terá que coordenar tudo". Em ambos os casos, essas atividades complementares farão uma grande diferença no mercado da indústria 4.0., pois compreenderia a áurea do contexto anterior quando relacionadas à criatividade.
Gráfico 6 - Marque as características mais ausentes nos alunos do Curso de Engenharia de Produção que seriam necessárias na indústria 4.0

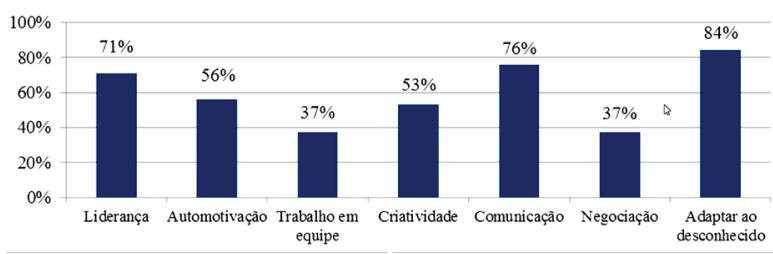

Fonte: dados da pesquisa (2017).

Sobre as características ausentes nos alunos, 4.0 (conforme o gráfico 6), as opções que mais se repetiram foi "Adaptar ao desconhecido" (84\%), "Comunicação" (76\%) e "Liderança" (71\%).

Os entrevistados que responderam à opção "Adaptar ao desconhecido" (84\%), justificaram que os alunos possuem receio de fazer trabalhos ou atividades que nunca fizeram antes. Também justificaram que, "quando sugerem uma atividade diferente, como a extracurricular, não recebe uma resposta positiva dos alunos". Já os entrevistados que escolheram a "Comunicação", comentaram sobre a dificuldade de muitos alunos em falar bem em público ou expor suas ideias de forma clara ou ética. Por último, os entrevistados que marcaram a "liderança" como característica ausente, justificaram que "muitos alunos confundem liderança com trazer todas as atividades para si mesmo" ou com "mandar todos fazerem sem levar em conta a limitação da equipe".

Gráfico 7 - Caso precisasse entrevistar um aluno de Engenharia de Produção para uma vaga de emprego em sua empresa. Qual seria a principal característica buscada? Por quê?

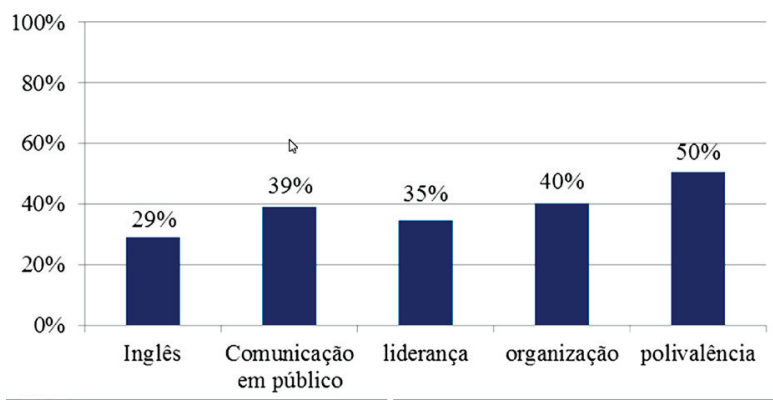

Fonte: dados da pesquisa (2017). 
No gráfico 7, foi perguntado qual característica os professores buscariam em um aluno caso tivesse uma oferta de emprego em sua empresa. Houve muitas respostas distintas, porém, entre as que mais se repetiram foram: "Polivalência" (50\%), "Organização" (40\%), "Comunicação em público" (39\%), "Liderança" (35\%) e "Inglês" (29\%).

Os professores que responderam sobre a "polivalência", justificaram que o aluno deve saber de tudo um pouco. Não adiantaria para eles que os alunos soubessem ou se especializassem somente em uma disciplina ou em uma área da empresa. Ele teria que conhecer todos os processos e, se possível, sugerir melhorias em todos os aspectos.

Entre os professores que responderam sobre a "organização" e a "comunicação em público", a justificativa foi que o funcionário deve organizar bem as ideias e saber transmiti-las para as outras pessoas.

Aos quesitos, "liderança" e "saber inglês" os professores remeteram essas características como sendo um quesito básico, ou seja, um pré-requisito, e, caso o funcionário não tivesse essas características, não seria levado em conta em uma seleção de emprego.

\section{CONCLUSÃO}

A indústria 4.0 deixou de ser uma idealização ou uma mera especulação futurista. Para a Associação de Engenheiros Brasil-Alemanha (BERNARDI, 2016), a Indústria 4.0 se posicionou definitivamente como tema de chances para a Alemanha, com o relançamento da plataforma Indústria 4.0 em Abril de 2015. A revolução, considerada como quarta revolução industrial, já está acontecendo e mudando a forma de se fazer negócio.

Este artigo teve como objetivo geral identificar, através da percepção docente, as características empreendedoras consideradas como mais importantes para a formação do Engenheiro de Produção que pretende atuar na indústria 4.0.

A formação de profissionais qualificados para atuar no mercado de trabalho, é um dos principais objetivos da educação superior, presente em muitas das missões das Instituições de Ensino Superior, deve acompanhar esse processo revolu- cionário e desenvolver nos alunos as capacidades técnicas e intelectuais para o desenvolvimento de suas carreiras profissionais.

Este artigo mostrou que, pela percepção docente, as características empreendedoras de "liderança", "adaptação ao desconhecido" e "boa comunicação" são as mais buscadas pela Indústria 4.0, e que a "apresentação de seminário", "projeto individual" e "projeto em equipe" são as metodologias de formação complementar que mais podem contribuir com o desenvolvimento das competências do aluno buscadas pela Indústria 4.0.

Foi identificado que $95 \%$ dos docentes consideram que o conceito da Indústria 4.0 é relevante para a formação do discente. Nesse sentido, há o entendimento considerável, do contexto profissional, o que "favorece" a complementação do conteúdo ministrado pelo docente ao contexto mercadológico atual.

Em relação à formação empreendedora, $100 \%$ dos docentes a consideram como importante para a diferenciação na formação do engenheiro de produção.

Verifica-se, ainda, que características importantes, mencionadas no referencial teórico, ainda não estão despertadas nos discentes pesquisados. Por meio da percepção do docente, verificou-se que a "adaptação ao desconhecido", "liderança" e "comunicação", são as características mais ausentes nos discentes, indo ao desencontro com o que o momento atual necessita para que o profissional tenha sucesso em suas ações.

O desafio está em mesclar fontes diferentes de aprendizados e experiências, bem como adaptar dentro da academia os conceitos advindos da Quarta Revolução Industrial e suas lacunas que ainda existem na formação profissional do graduando, especialmente, no foco deste estudo, o aluno do Curso de Engenharia de Produção.

Com esse advento, as demandas para pesquisa e desenvolvimento oferecerão oportunidades para profissionais tecnicamente capacitados, com formação multidisciplinar para compreender as relações existentes dentro de um contexto de fábrica inteligente.

Todo este aparato tecnológico funcionará sob o comando de seres humanos, ainda que robôs e sistemas autômatos realizem 
boa parte das tarefas. E, além das características inerentes ao novo profissional - comunicação interpessoal, flexibilidade e capacidade de trabalho em equipe - há novos atributos e comportamentos a serem trabalhados. Entre eles, estão conhecimento em internet das coisas, multidisciplinaridade e capacidade de criar soluções ao mesmo tempo tecnológicas e sustentáveis. Também se destaca a capacidade de ter senso crítico. É fundamental deter uma capacidade analítica capaz de cruzar e interpretar dados ao mesmo tempo em que se tomam decisões rápidas, muitas delas em tempo real (VDI, 2019, on-line).

Neste panorama, recomenda-se que novos estudos sejam realizados a fim de aprofundar o entendimento da relação entre os discentes e os docentes, em seus contextos educacionais. Contribuir com novas ideias para as políticas de ensino a fim de promover a inserção de profissionais dentro de um "novo" mercado, e que estes possam traduzir as demandas advindas da "internet das coisas" em oportunidades para perpetuar o seu sucesso profissional, tanto para o lado pessoal como para o benefício da comunidade a que ele pertencer. Estudar, sempre, métodos de ensino que reforcem essas habilidades no discente do Curso de Engenharia de Produção, bem como, se antever os desafios que eles irão enfrentar após a formação, quando se tornarem, por fato e direito, Engenheiros de Produção.

\section{REFERÊNCIAS}

ABEPRO. Associação Brasileira de Engenharia de Produção. Engenharia de Produção:

Grande Área e Diretrizes Curriculares. Documento elaborado nas reuniões do grupo de trabalho de graduação em Engenharia de Produção, promovidas pela ABEPRO e realizadas durante o XVII Encontro Nacional de Engenharia de Produção (XVII ENEGEP, Gramado, RS, 6 a 9 de outubro de 1997) e durante o III Encontro de Coordenadores de Cursos de Engenharia de Produção (III ENCEP, Itajubá, 27 a 29 de abril de 1998). 1998. Disponível em: http://www.abepro.org.br/arquivos/websites/1/diretrcurr19981.pdf. Acesso em: 1 jan. 2019.
ABREU, M. C.; MASETTO, M. T. O professor universitário em aula: práticas e princípios teóricos. 5. ed. São Paulo: MG Ed. Associados, 1985.

AIRES, R. W. A.; MOREIRA, F. K.; FREIRE, P. $\mathrm{S}$. Indústria 4.0: competências requeridas aos profissionais da quarta revolução industrial. In: CONGRESSO INTERNACIONAL DE CONHECIMENTO E INOVAÇÃO, 7., 2017, Foz do Iguaçu. Anais [...]. Foz do Iguaçu: CIKI, 2017.

ALMEIDA, P. R. de. O Brasil e a nanotecnologia: rumo à quarta revolução industrial. Revista Espaço Acadêmico, v. 6, n. 52, set. 2005.

AMBONI, N. et al. Interdisciplinaridade e complexidade no curso de graduação em Administração. Cad. EBAPE.BR, Rio de Janeiro, v. 10, n. 2, p.302-328, jun. 2012. Disponível em: http://www. scielo.br/pdf/cebape/v10n2/v10n2a05.pdf. Acesso em: 1 jan. 2019.

BALASINGHAM, K. Industry 4.0: securing the future for german manufacturing companies. 2016. Dissertação (Mestrado) - University of Twente, Twente, 2016.

BERBEL, N. A. N. As metodologias ativas e a promoção da autonomia de estudante. Semina: Ciências Sociais e Humanas, Londrina, v. 32, n. 1, p. 25-40, jan./jun. 2011. Disponível em: http:// www.proiac.uff.br/sites/default/files/documentos/ berbel_2011.pdf. Acesso em: 29 jan. 2019.

BERNARDI, N. O aluno do agora. Revista Engenharia Brasil-Alemanha, São Paulo, p. 40-42, nov. 2016. Disponível em: http://www.vdibrasil. com/wp-content/uploads/revista-dia-da-engenharia-2016.pdf. Acesso em: 27 fev. 2019.

BURKE, Peter. Uma história social do conhecimento: de Gutemberg. Rio de Janeiro: Jorge Zahar, 2003.

BORDENAVE, J. D.; PEREIRA, A. M. Estratégias de ensino-aprendizagem. 4. ed. Petrópolis: Vozes, 1982. 
COELHO, P. M. N. Rumo à Indústria 4.0. 2016. 62 f. Dissertação (Mestrado em Engenharia e Gestão Industrial) - Faculdade de Ciências e Tecnologia, Universidade de Coimbra, Coimbra, 2016.

CONSELHO NACIONAL DE EDUCAÇÃO (Brasil). Resolução CNE/CES 11, de 11 de março de 2002. Institui Diretrizes Curriculares Nacionais do Curso de Graduação em Engenharia. Portal MEC, 2002. Disponível em: http://portal.mec. gov.br/cne/arquivos/pdf/CES112002.pdf. Acesso em: 27 fev. 2019.

COSTA, M. T. G.; CARVALHO, L. C. A educação para o empreendedorismo como facilitador da inclusão social: um caso no ensino superior. Revista Lusófona de Educação, v. 19, p. 103-118, 2011. Disponível em: http://revistas.ulusofona.pt/index. php/rleducacao/article/view/2844/2161. Acesso em: 4 maio 2013.

CHIAVENATO, I. Introdução à teoria geral da administração. Rio de Janeiro: Elsevier, 2003.

DELOITTE. Industry 4.0: challenges and solutions for the digital transformation and use of exponencial technologies. [S. l.: s. n.], 2014.

DELORS, J. et al. Educação: um tesouro a descobrir: relatório para a UNESCO da Comissão Internacional sobre Educação para o Século XXI. São Paulo: Cortez; Brasília, DF: UNESCO, 1998.

DORNELAS, J. Empreendedorismo: transformando ideias em negócios. 4. ed. Rio de Janeiro: Elsevier, 2012.

ENDEAVOR BRASIL. O que é Empreendedorismo: da inspiração à prática. 2018. Disponível em: https://endeavor.org.br/sem-categoria/o-que-e-empreendedorismo-da-inspiracao-a-pratica/?gclid=Cj0KCQiAnNXiBRCoARIsAJe_1 cpF4mLEute6T7QPQa11M1L3uDcrzDHFk6jBzIiWvXpxC74o8oUdTJUaAg5UEALw_wcB. Acesso em: 28 dez. 2018.
FERREIRA, E. C. A sobrevivência no mundo do downsizing. In: SIMPÓSIO DE ENGENHARIA DE PRODUÇÃO, 11., 2014, São Paulo. Anais [...]. São Paulo, 2004. Disponível em: http:// www.simpep.feb.unesp.br/anais/anais 11/copiar. php?arquivo $=536$-Ferreira $\% 20$ E.C.A $\% 20$ sobreviv\%EAncia\%20no\%20mundo\%20do\%20downsizing.pdf. Acesso em: 30 jan. 2019.

FILION, L. J. Empreendedorismo: empreendedores e proprietários-gerentes de pequenos negócios. Revista de Administração da Universidade de São Paulo, v. 34, n. 2, p. 5-28, 1999.

GUIMARÃES, S. E. R. Avaliação do estilo motivacional do professor: adaptação e validação de um instrumento. 2003. Tese (Doutorado em Educação) - Programa de Pós-Graduação em Educação, Universidade Estadual de Campinas, Campinas.

GUIMARÃES, E. T; GOUlART, I. B. Competências dos alunos egressos do Curso superior de tecnologia em Gestão da produção industrial - estudo de caso UNINCOR. Revista da Universidade Vale do Rio Verde, Três Corações, v. 9, n. 2, p. 296-327, ago./dez. 2011. Disponível em: https:// dialnet.unirioja.es/descarga/articulo/4002701.pdf. Acesso em: 1 jan. 2019.

JAPIASSU, H. Interdisciplinaridade e patologia do saber. Rio de Janeiro: Imago, 1976.

KHAN, S. Um mundo, uma escolar: a educação reiventada. Rio de Janeiro: Intriseca LTDA, 2013.

MAGRANI, E. A internet das coisas. Rio de Janeiro: FGV Editora, 2018.

MARKHAM, T.; LARMER, J.; RAVITZ, J. (org.). Aprendizagem baseada em projetos: guia para professores de ensino fundamental e médio. Porto Alegre: Artmed, 2008.

MASETTO, M. T. Aulas vivas: tese e prática de Livre Docência. 2 ed. São Paulo: MG Ed. Assoc., 2001. 
MASLOW, A. H. Uma teoria da motivação humana. In: BALCÃO, Y.; CORDEIRO, L. L. (org.). $\mathbf{O}$ comportamento humano na empresa. Rio de Janeiro: FGV, 1975. p. 337-366.

MCKINSEY. Industry 4.0 at McKinsey's model factories: get ready for the disruptive wave. [S. $l$. : s. n.], 2016.

MEDINA, C. Qual o é tamanho da amostra que eu preciso? 2013. Disponível em: http://www.netquest.com/br/blog/qual-e-o-tamanho-de-amostra-que-preciso/. Acesso em: 22 dez. 2014.

MORAIS, R. R. de; MONTEIRO, R. A indústria 4.0 e o impacto na área de operações: Um ensaio. In: SIMPÓSIO INTERNACIONAL DE GESTÃO DE PROJETOS, INOVAÇÃO E SUSTENTABILIDADE, 5., 2016, São Paulo. Anais [...]. São Paulo, 2016.

ODERICH, C. Gestão de competências gerenciais: noções e processos de desenvolvimento. In: RUAS, R. L.; ANTONELLO, C. S.; BOFF, L. H. (org.). Aprendizagem organizacional e competências. Porto Alegre: Bookman, 2005.

OLIVEIRA, Djalma de Pinho Rebouças de. Gestão para resultados: atuação, conhecimentos, habilidades. São Paulo: Atlas, 2010.

PAZ, F. J.; MACHADO, P. S. A importância do treinamento para o desenvolvimento organizacional: um estudo em organizações do agronegócio de dom pedrito. Revista da Jornada de Pós-Graduação e Pesquisa-Congrega Urcamp, p. 47-63, 2016. Disponível em http://trabalhos.29 jun.2017. congrega.urcamp.edu.br/index.php/jpgp/article/ view/704/1026. Acesso em: 29 jan. 2019.

PEIRIS, I. K.; AKOORIE, M. M.; SINHA, P. International entrepreneurship: a critical analysis of studies in the past two decades and future directions for research. Journal of International Entrepreneurship, New York, v. 10, n.4, p. 279-324, 2012. Disponível em: http://link.springer.com/article/10.1007/ s10843-012-0096-3\#. Acesso em: 5 maio 2013.
PENÃ, V. Investigating the increasing role of public social networks within the innovation process of large, multi-national corporations. In: FOURTH ANNUAL GENERAL BUSINESS CONFERENCE PROCEEDINGS, 4., 2012, Sam Houston State University. College of Business Administration Smith-Hutson Business Building. Huntsville, Texas, USA. Editor: Steve Nenninger. Proceedings [...]. Texas, 2012. p. 13-14, 2012.

PIRATELLI, C. L. A engenharia de produção no Brasil. In: CONGRESSO BRASILEIRO DE ENSINO DE ENGENHARIA, 33., 2005, Campina Grande. Anais [...]. Campina Grande: ABENGE, 2005. p. 1-12.

RIBEIRO, L. R. C. et al. Uma experiência com a PBL no ensino de engenharia sob a ótica dos alunos. São Paulo: COBENGE, 2003.

SCHWAB, K. A quarta revolução industrial. São Paulo: Edipro, 2016.

SILVA, K. T. M. da; MASCARENHAS, I. P. Gamificação como experiência de aprendizagem inovadora. Uma pesquisa-ação no curso de administração de empresas da Unichristus em Fortaleza-CE. In: ENCONTRO NACIONAL DE CURSOS DE GRADUAÇÃO EM ADMINISTRAÇÃO, 27., 2016, Campinas. Anais [...]. Campinas: Universidade Presbiteriana Mackenzie, 2016.

VDI. Associação de Engenheiros Brasil - Alemanha. Você tem o perfil que a Indústria 4.0 está precisando? Disponível em: http://www.vdibrasil.com/ger/perfil-que-industria-4-0-esta-precisando/. Acesso em: 27 fev. 2019.

YIN, R. K. Estudo de caso: planejamento e métodos. 5. ed. Porto Alegre: Bookman, 2015. 